\title{
6 \\ Geographic Determinants of Carbon Markets (CDM)
}

\subsection{Introduction}

Global warming has emerged as one of the most critical issues of our age, and a key issue in the global economic and environmental debates. In recent years, the global carbon market has become a newly developed area for research and practice. It essentially consists of allowance-based markets and project-based markets which use market-based mechanisms to allocate and trade carbon credits that represent $\mathrm{CO}_{2}$ emission reductions in order for the participants to meet their compliance requirements at the lowest possible cost. In allowance-based markets, the buyers purchase emission allowances created and allocated (or auctioned) by regulators under cap-and-trade regimes like Assigned Amount Units (AAUs) under the Kyoto Protocol, or EU Allowances (EUAs) under the EU Emissions Trading Scheme (EU ETS). Within project-based markets, the buyers purchase emission credits from investing into a project that can demonstrate a reduction of $\mathrm{CO}_{2}$ emissions in comparison to the level of emissions in the absence of the project investment. The most notable examples of such activities are the Clean Development Mechanism (CDM) and the Joint Implementation (JI) schemes under the Kyoto Protocol.

As part of the emerging global carbon market, CDM is the only Kyoto mechanism which involves developing countries in the climate change negotiations. Under the Kyoto Protocol, the CDM is designed to realize the benefits in terms of capital flow, technological transfer, sustainable development and cost-effective emission abatement. However, the geographic distribution of CDM projects by host country and region has been found to be highly uneven. This chapter addresses the issue of whether the geographic endowments in the host countries matter for 
CDM development using recently developed spatial econometric techniques, with an aim of encouraging further research into economic, institutional and policy determinants of CDM development.

In response to climate change, the global community adopted the Kyoto Protocol in 1997. It came into force in February 2005 and calls for legally binding limits on the greenhouse gas (GHG) emissions by developed countries (or Annex I countries) by at least 5\% in comparison to the 1990 levels over the first commitment period (i.e. 2008-12). Although each Annex I country is assigned an amount of $\mathrm{CO}_{2}$ equivalents (expressed in Assigned Amount Units, AAUs) to be used over the period 2008-12, some Annex I countries still face a projected shortfall in GHG emission reductions. To meet their commitments, these countries usually seek emission reduction credits through the three "flexibility mechanisms" defined under the Kyoto Protocol: International Emission Trading (IET), Joint Implementation (JI) and the CDM.

The CDM is defined in Article 12 of the Kyoto Protocol, and is the only such mechanism that involves developing countries. By joining in the CDM, on the one hand, developing countries can get access to significant foreign capital flows and technology transfer to achieve more sustainable, less GHG-intensive pathways of development. On the other hand, the Annex I countries can purchase and utilize the emission reduction credits, called Certified Emission Reductions (CERs), generated from CDM projects towards meeting their quantified emission targets under the Protocol.

The geographic distribution of CDM projects by host country and region has been observed as being lopsided, in terms of both the number of projects and the volume of credits. More specifically, two regions, Asia and the Pacific, and Latin America, together dominate the distribution of CDM projects and CER flows, such that by the end of September 2008 China, India, Brazil and Mexico accounted for 45\%, 23\%, 5\% and 1\% of CDM projects, respectively. ${ }^{99}$ Developing countries with large populations and economies are expected to account for a large number of CDM projects and CER flows. However, do countries with particular geographic characteristics like higher absolute latitudes, higher elevations and richer resource endowments have more CDM projects and CER flows?

Economists have long noted the crucial role of geography in economic development: transport costs, human health, agricultural productivity and ownership of natural resources. The climate theory of underdevelopment has been widely recognized in the sense that certain geographic endowments have an adverse impact on economic development. For 
example, some geographic endowments (like mineral resource endowments) may influence the inputs into the production function, while others (like tropical location) may make the production technologies much harder to employ and affect technological development in the very long term (Sachs, 2003; Sachs and Warner, 1995; Diamond, 1997; Gallup et al. 1999).

While there is considerable research examining the sustainable development impacts of CDM development, much less work has aimed to explore the fundamental determinants of CDM development across countries. This chapter evaluates whether cross-sectional differences in CDM development can be explained by cross-sectional differences in geographic characteristics and resource endowments, once controlling for other potential factors.

The cross-country experience of CDM project selection and foreign direct investment indicates the existence of neighbourhood effects or spillovers among countries. ${ }^{100}$ The neighbourhood effects of CDM projects, together with "a new and deeper version of globalization" since 1970 (Crafts, 2000) which causes a closer interdependence across countries, suggest that spatial correlation is an important phenomenon to be considered in this application. By employing the spatial econometric method recently developed by Kelejian and Prucha (2010), this chapter conducts a cross-country study on 48 developing countries over the period from December 2003 up to September 2008.

This research has led to two significant findings. First, it provides evidence that positive spatial dependence among observations exists in this context. More specifically, the CDM credit flows in a country increase by about 0.34 to 0.48 units if those in its neighbouring countries increase by one unit; and countries with larger CDM credit flows tend to be geographically clustered with other large CDM host countries. Second, by allowing for spatial dependence and accounting for the size of the economy (initial population and initial GDP per capita), this research finds that absolute latitude and elevation have positive impacts on CDM credit flows, suggesting that countries further from the equator and having higher elevations tend to initiate more CDM projects and issue more CDM credit flows. Larger service exporting countries seem to have more advantages in getting access to CDM projects, while on the contrary, larger natural resource exporting countries have smaller CDM credit flows, indicating that natural resource abundance may not necessarily be attractive to CDM projects.

This finding sheds light on the geographic determinants of uneven $\mathrm{CDM}$ project development across countries. It has rich implications 
for developing countries in terms of international cooperation and national capacity building in order to access effectively the CDM for their national sustainable development objectives. This research also suggests that the geographic considerations should be introduced into the econometric and theoretical cross-country studies of climate change and mitigation.

The remainder of the chapter proceeds as follows. Section 6.2 describes the data and shows some stylized facts. The empirical results are presented in Section 6.4, following a description of econometric methods in section 6.3. Section 6.5 concludes.

\subsection{Data and stylized facts}

This section outlines the measures and data for CDM, key geographic variables and the control variables.

The dependent variable is the Clean Development Mechanism credit flows, simply denoted by CDM. The indicator for CDM is the average of the Certified Emission Reductions (2012 kCERs) generated by the CDM projects in the pipeline over the period from December 2003 to September 2008. ${ }^{101}$ One country has one observation. To diminish the impacts of outliers and measurement errors, it is taken in logs. The CDM projects in the pipeline include not only those called "confirmed projects" which have been at the registration stage, having either registered or requested registration, but also those called "probable projects" which are at the validation stage, waiting to be registered and implemented over the next three years. One CER equals to one metric tonne of $\mathrm{CO}_{2}$ e. ${ }^{102}$ Data on CER flows are from the UNEP Risoe Centre (2008).

To examine the impacts of particular geographic characteristics on CDM project development, three geographic variables - absolute latitude, elevation and land area - are considered. Absolute latitude (LATITUDE) equals the absolute distance from the equator of a country. The closer the countries are to the equator, the more tropical climate they have. Elevation (ELEV) is the mean elevation (metres above sea level) calculated in geographic projection, and used in logs. The land area $(A R E A)$ in square kilometres for each country is in logs. Data on latitude, elevation and land area are taken from the physical factors dataset of Center for International Development (CID) at Harvard University. ${ }^{103}$

To assess the role of natural resource endowments, this research uses two groups of variables. One group of variables consists of dummies for the manufactured goods exporting countries (EXPMANU), service 
exporting countries (EXPSERV) and non-fuel primary goods exporting countries (EXPPRIM) from the Global Development Network of the World Bank (GDN). The other group of variables, taken from Isham et al. (2005), includes dummies for the exporters of point source natural resources (e.g. oil, diamonds, plantation crops) (RESPOINT), "diffuse" natural resources (e.g. wheat, rice, animals) (RESDIFF) and coffee/cocoa natural resources (RESCOFF).

Control variables included in this analysis are the initial GDP per capita (GDP03), the initial population (POP03), an ethnic fractionalization index (ETHNIC), a religious fractionalization index (RELIGION) and legal origin dummies, COMLEG and CIVLEG.

The inclusion of the initial GDP per capita and population is to control for the size of the economy where GDP03 is the real GDP per capita in 2003 in constant 2000 US\$ (chain series), and POPO3 is the population in 2003. Both GDP03 and POP03 are used in logs and taken from the Penn World Table 6.2 in Heston et al. (2006). The variables ETHNIC and RELIGION characterize social divisions and cultural differences. The data on ETHNIC and RELIGION are taken from Alesina et al. (2003). ${ }^{104}$ COMLEG is the Common Law legal origin dummy for countries with British legal origin, while CIVLEG is the Civil Law legal origin dummy for countries with French, German or Scandinavian legal origins. Data on CIVLEG and COMLEG are from the GDN. 105

The sample includes $48 \mathrm{CDM}$ host countries from Asia and the Pacific, Latin America and the Caribbean, the Middle East and North Africa, SubSaharan Africa and Europe and Central Asia as listed in the Appendix Table A6.1. Countries with fewer than three monthly non-zero observations (up to September 2008) in terms of credit flows (2012 kCERs) have been removed.

Figure 6.1 presents the scatter plots between CDM credit flows and absolute latitude and elevation, respectively. Despite the existence of outliers such as China and Paraguay, the positive associations between absolute latitude and CDM credit flows, and between elevation and CDM credit flows, can be observed. Countries with higher absolute latitudes and higher elevations are more likely to have more CDM projects as well as CER credit flows.

Figure 6.2 demonstrates, in the upper chart, that CDM credit flows in coffee exporters, diffuse exporters and point source exporters are in general smaller than those in the non-exporters of the relevant resources. The lower chart shows that manufactured goods exporters, service exporters and non-fuel primary goods exporters tend to have fewer CDM credit flows in comparison to their counterparts. 
166 Determinants of Financial Development
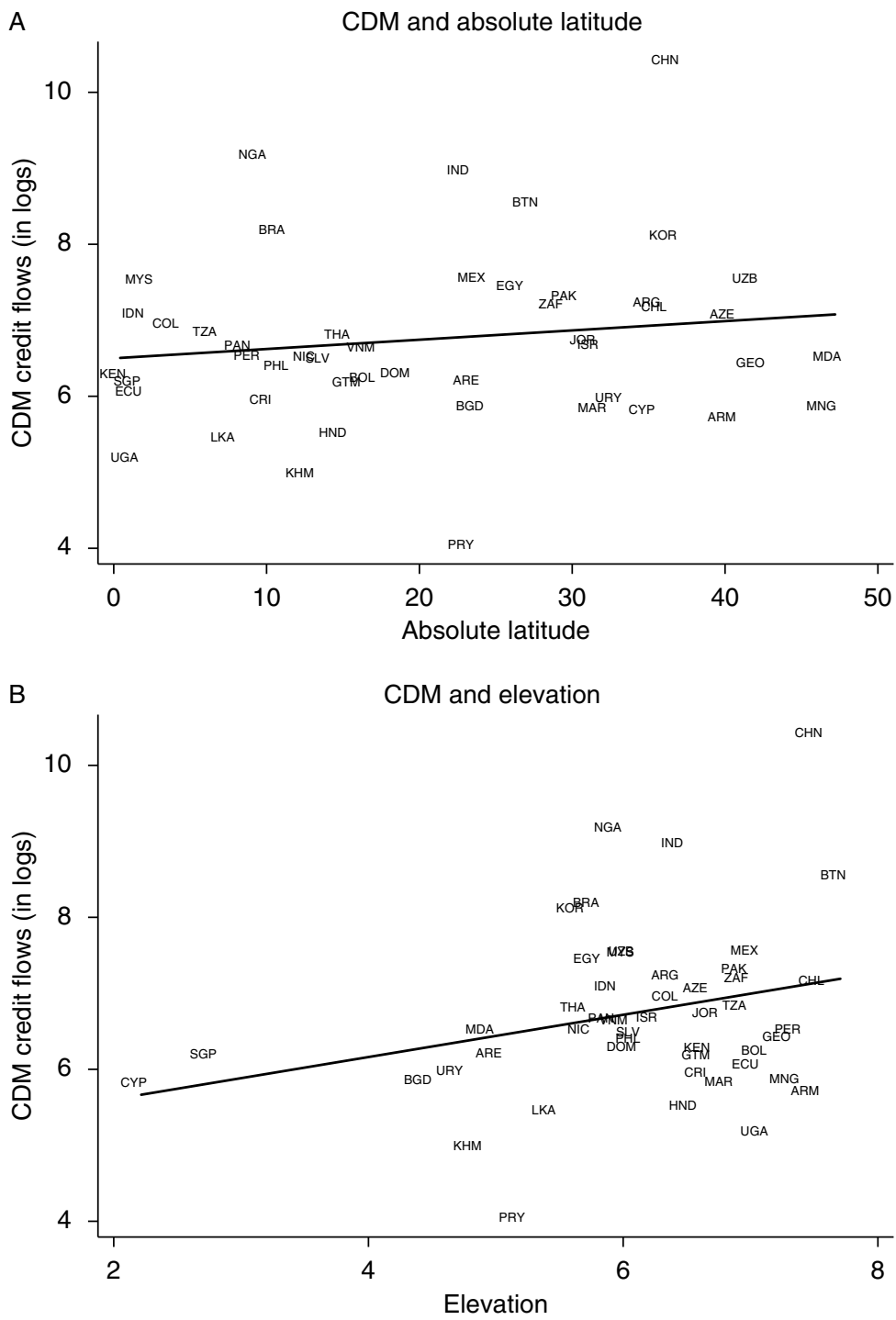

Figure 6.1 Scatter plots of CDM and geography

Note: Variables and data sources are described in the text. These figures show scatter plots of absolute latitude and elevation against CDM credit flows (CERs). 

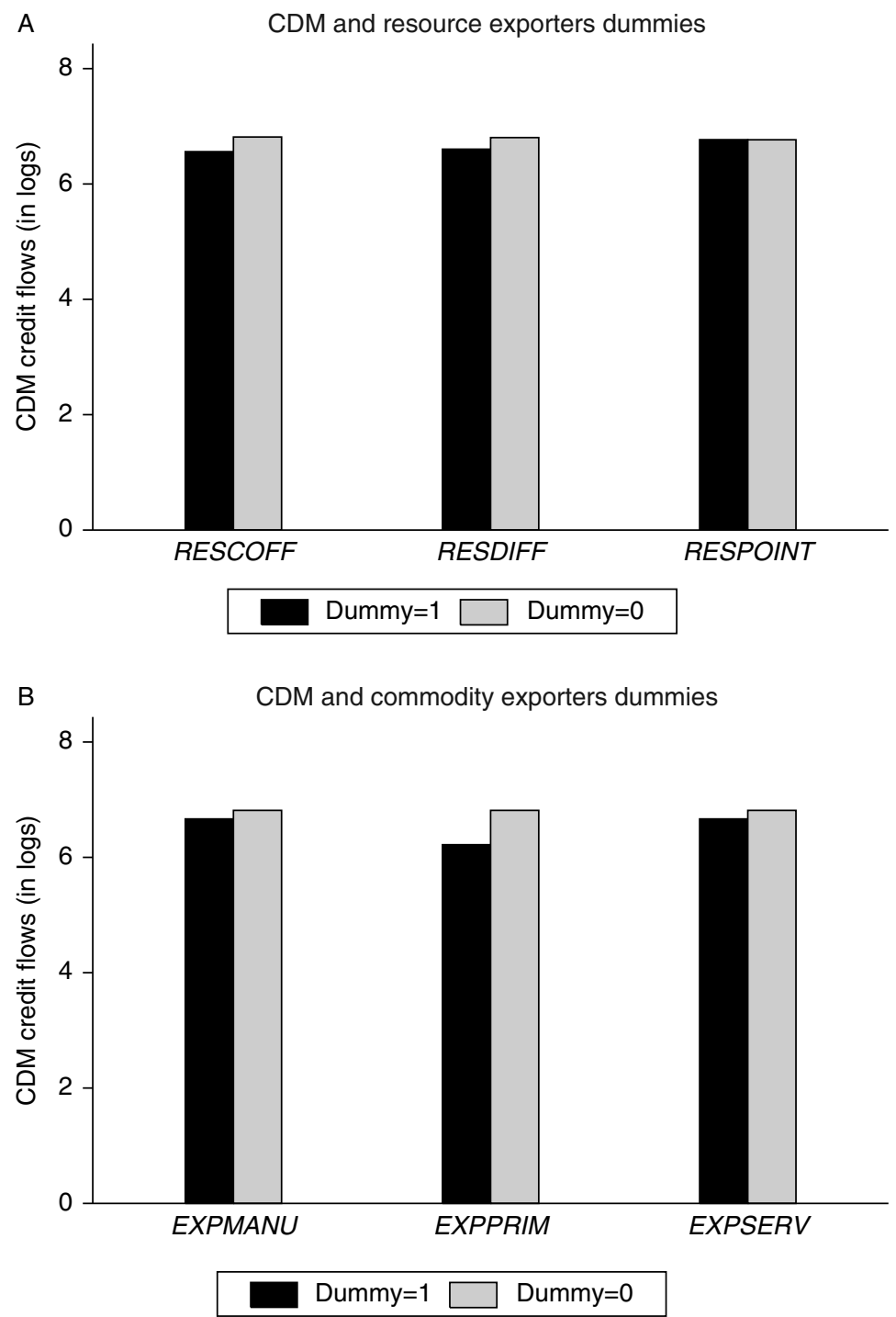

Figure 6.2 CDM and resource endowments

Note: Variables and data sources are described in the text. These figures show the comparisons of CDM credit flows (CERs) for different dummies of exporters. 


\subsection{Econometric method: Spatial econometric approach}

To study the impacts of geography on CDM project development, this research conducts a cross-sectional study allowing for spatial correlation on 48 countries over the period from December 2003 to September 2008. It starts from an Ordinary Least Square (OLS) estimation on a basic model:

$$
\begin{aligned}
Y_{n} & =X_{n}^{\prime} \beta+\epsilon_{n} \\
n & =1,2, \ldots 48
\end{aligned}
$$

where $Y_{n}$ is an $n \times 1$ ( $n$ is the number of cross section units) vector of observations on dependent variable $C D M$.

$X_{n}$ is an $n \times k$ matrix of observations on $k$ exogenous explanatory variables which consist of geographic variables (LATITUDE, ELEV, AREA, EXPSERV, EXPPRIM, RESPOINT, RESDIFF and RESCOFF) and the control variables including GDP03, POPO3, ETHNIC, RELIGION and legal origin dummies (CIVLEG, COMLEG).

$\beta$ is a $k \times 1$ parameter vector. The error term $\epsilon_{n}$ is an $n \times 1$ vector with $E(\epsilon)=0$ and $E\left(\epsilon \epsilon^{\prime}\right)=\delta^{2} I$.

The OLS specification typically follows the assumption of no spatial interdependence or spatial correlation. However, spatial dependence associated with social interactions or unobserved common shocks has been widely recognized. On the one hand, considerable research has been done to explore the implications of social or spatial interactions in terms of neighbourhood effects, spatial spillovers or networks effects (Manski, 2000; Brock and Durlauf, 2001). The fact that one agent's decision variable is affected by those of other agents is typically formulated as a spatial lagged dependent variable, or a spatial lag term to be included in the right-hand side of the regression model. In the context of financial liberalization and reform, Abiad and Mody (2005, henceforth AM) find that regional diffusion in terms of the liberalization gap from the regional leader is significantly associated with the policy change.

On the other hand, in a globalized world, common shocks - either observed global shocks like macroeconomic shocks or unobserved global shocks like technological shocks - are believed to cause closer interdependence across countries. Andrews (2005) analyses the impact of common shocks in the cross section regression in which the observations are i.i.d. across population units conditional on common shocks, providing a general framework for spatially correlated errors. ${ }^{106}$ In examining the origins of financial openness, Quinn and Inclán (1997) argue that the common trend, such as changes in consumer tastes and technology, may 
substantially affect government liberalization policies as "fundamental but unobservable forces".

Obviously, the OLS estimation provides the foundation for spatial analysis. This research incorporates the spatial correlation structure into the basic linear model to account for both spatial lag dependence and spatial error dependence.

A spatial lag model is a formal specification of spatial lag dependence due to the presence of social and spatial interactions. Its basic form is the mixed regressive, spatial autoregressive model: ${ }^{107}$

$$
Y_{n}=X_{n}^{\prime} \beta+\lambda W_{n} Y_{n}+\epsilon_{n},|\lambda|<1
$$

where $\lambda$ is the spatial autoregressive coefficient or spatial interdependence coefficient, measuring the dependence of $Y_{i}$ on neighbouring $Y_{n}$. $W_{n}$ is an $n \times n$ spatial weighting matrix of known constants, reflecting the neighbouring relationships with zero across diagonals and a row-standardized form. The added variable, $\lambda W_{n} Y_{n}$, an average of the neighbouring values, is referred to as a spatially lagged dependent variable, or a spatial lag of $Y_{n}$. The error term, $\epsilon_{n}$, is an $n \times 1$ idiosyncratic error vector, assumed to be distributed independently across the cross-sectional dimension with zero mean and constant variances $\sigma_{\epsilon}^{2}$.

When the spatial dependence exists in the error term due to unobserved effects of common shocks (for example, macroeconomic shocks, political shocks or environmental shocks), a spatial error model can be used as follows: ${ }^{108}$

$$
\begin{aligned}
& Y_{n}=X_{n}^{\prime} \beta+u_{n} \\
& u_{n}=\rho M_{n} u_{n}+\epsilon_{n},|\rho|<1
\end{aligned}
$$

where $\rho$ is the spatial autoregressive coefficient, measuring the amount of spatial correlation in the errors. $M_{n}$ is the spatial weighting matrix, may or may not be the same as $W_{n} . u_{n}$ is spatially correlated residuals and $\epsilon_{n}$ is the independent and identically distributed disturbances with zero mean and constant variances $\sigma_{\epsilon}^{2} . M_{n} u_{n}$ is known as a spatial lag of $u_{n}$.

By plugging the error term of the spatial error model (6.3) into the spatial lag model (6.2), one can generate the spatial autoregressive model with autoregressive disturbances of order $(1,1)$, that is the $\operatorname{SARAR}(1,1)$ model, as follows,

$$
\begin{aligned}
& Y_{n}=X_{n} \beta+\lambda W_{n} Y_{n}+u_{n}, \quad|\lambda|<1 \\
& u_{n}=\rho M_{n} u_{n}+\epsilon_{n}, \quad|\rho|<1
\end{aligned}
$$


The above model is believed to be very general in the sense that it allows for spatial spillovers stemming from endogenous variables, exogenous variables and disturbances. It can be rewritten as:

$$
\begin{aligned}
& Y_{n}=Z_{n}^{\prime} \delta+u_{n} \\
& u_{n}=\rho M_{n} u_{n}+\epsilon_{n}
\end{aligned}
$$

where $Z_{n}^{\prime}=\left[X_{n}, W_{n} Y_{n}\right], \delta=\left[\beta^{\prime}, \lambda\right]^{\prime}$

The corresponding transformed model can be obtained by premultiplying (6.5) by $I_{n}-\rho M_{n}$,

$$
Y_{n^{*}}(\rho)=Z_{n^{*}}^{\prime}(\rho) \delta+\epsilon_{n}
$$

where $Y_{n^{*}}(\rho)=Y_{n}-\rho M_{n} Y_{n}$ and $Z_{n^{*}}(\rho)=Z_{n}-\rho M_{n} Z_{n}$.

To estimate a general spatial model like (6.4), a number of approaches have been proposed in the literature, for example, Kelejian and Prucha (1998, 1999), Kelejian et al. (2004), Lee (2003, 2007) and Lee and Liu (2006). However, these approaches in general assume that the innovations in the disturbance process are homoscedastic, which may not hold in many applications. To fill this gap, Kelejian and Prucha (2010) develop a Generalized Spatial Two-Step Least Square (GS2SLS) estimator with a three-stage procedure of inference for the $\operatorname{SARAR}(1,1)$ model that allows for unknown heteroscedasticity in the innovations. Arraiz et al. (2010) provide simulation evidence showing that, when the disturbances are heteroscedastic, the GS2SLS estimator produces consistent estimates while the ML estimator produces inconsistent estimates.

This chapter examines the impacts of geography on CDM development within a general $\operatorname{SARAR}(1,1)$ framework. To estimate the $\operatorname{SARAR}(1,1)$ model, it employs the three-stage procedure of Kelejian and Prucha (2010), which can be summarized in the following.

In the FIRST step, the model (6.5) is estimated by the Two-Stage Least Square (2SLS) estimator using the instrument $H_{n}$. The instrument $H_{n}$ is the matrix of instruments which is formed as a subset of linearly independent columns of $\left(X_{n}, W_{n} X_{n}, W_{n}^{2} X_{n} \ldots\right)$. The first step 2SLS estimator is as follows:

$$
\begin{aligned}
& \widetilde{\delta_{n}}=\left(Z_{n}^{\prime} Z_{n}\right)^{-1} \widetilde{Z_{n}^{\prime} Y_{n}} \\
& \tilde{u_{n}}=Y_{n}-Z_{n} \widetilde{\delta_{n}}
\end{aligned}
$$

where $\tilde{Z_{n}}=P_{H} Z_{n}=\left[X_{n}, \widetilde{W_{n} Y_{n}}\right], \widetilde{W_{n} Y_{n}}=P_{H} W_{n} Y_{n}$ and $P_{H_{n}}=$ $H_{n}\left(H_{n}^{\prime} H_{n}\right)^{-1} H_{n}^{\prime}$. 
In the SECOND step, $\rho_{n}$ and $\sigma_{\epsilon}^{2}$ are estimated, where $\rho_{n}$ is the spatial autoregressive parameter and $\sigma_{\epsilon}^{2}$ is the variance of the innovation term $\epsilon_{n}$. They are estimated by applying GMM to the model (6.5), based on the 2SLS residuals $\tilde{u_{n}}$ obtained from the First step. More specifically, this estimator is $\tilde{\rho_{n}}$, defined as

$$
\tilde{\rho_{n}}=\underset{\rho \in\left[-a^{\rho}, a^{\rho}\right]}{\arg \min }\left[m\left(\rho, \widetilde{\delta_{n}}\right)^{\prime} \tilde{\Psi}_{n}^{-1} m\left(\rho, \widetilde{\delta_{n}}\right)\right]
$$

where $\widetilde{\Psi}_{n}$ is an estimator of the variance-covariance matrix of the limiting distribution of the normalized sample moments $n^{\frac{1}{2}} m\left(\rho, \widetilde{\delta_{n}}\right)$.

$$
\begin{aligned}
& m\left(\rho, \widetilde{\delta_{n}}\right)=g_{n}\left(\widetilde{\delta_{n}}\right)-G_{n}\left(\widetilde{\delta_{n}}\right) \rho \rho^{2}
\end{aligned}
$$

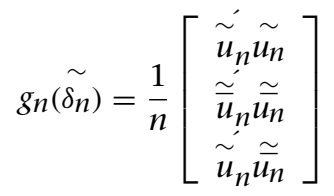

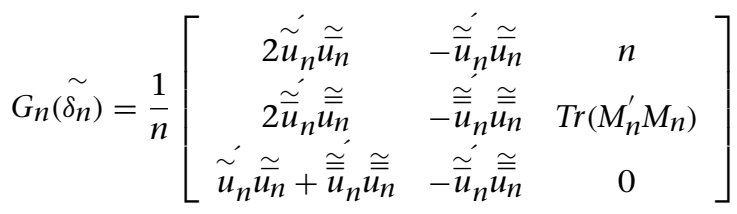

$$
\begin{aligned}
& \widetilde{u_{n}}=M_{n} \widetilde{u_{n}} \\
& \stackrel{\widetilde{u_{n}}}{\cong} M_{n}^{2} \widetilde{u_{n}}
\end{aligned}
$$

In the THIRD step, $\delta$ in the transformed model (6.6) can be estimated by a generalized spatial 2SLS procedure (GS2SLS) after replacing $\rho$ by $\tilde{\rho_{n}}$. The GS2SLS estimator of $\delta$ is defined as:

$$
\hat{\delta_{n}}\left(\widetilde{\rho_{n}}\right)=\left[\hat{Z}_{n^{*}}\left(\widetilde{\rho_{n}}\right)^{\prime} Z_{n^{*}}\left(\widetilde{\rho_{n}}\right)\right]^{-1}\left[\hat{Z}_{n^{*}}\left(\widetilde{\rho_{n}}\right) Y_{n^{*}}\left(\widetilde{\rho_{n}}\right)\right]
$$

where $Y_{n^{*}}\left(\widetilde{\rho_{n}}\right)=Y_{n}-\widetilde{\rho_{n}} M_{n} Y_{n}, Z_{n^{*}}\left(\widetilde{\rho_{n}}\right)=Z_{n}-\widetilde{\rho_{n}} M_{n} Z_{n}$, and $\hat{Z}_{n^{*}}\left(\widetilde{\rho_{n}}\right)=P_{H}$ $Z_{n *}\left(\tilde{\rho_{n}}\right)$.

\subsection{Empirical evidence}

This section presents the empirical evidence for the impacts of various geographic variables on CDM credit flows. Before proceeding to detailed 
econometric analysis, we briefly test for spatial dependence of CDM credit flows across countries with evidence presented in Figure 6.3 and Table 6.1.

Figure 6.3 plots the averaged CDM credit flows of all sample countries against the distance to the country with the largest CDM credit flows in
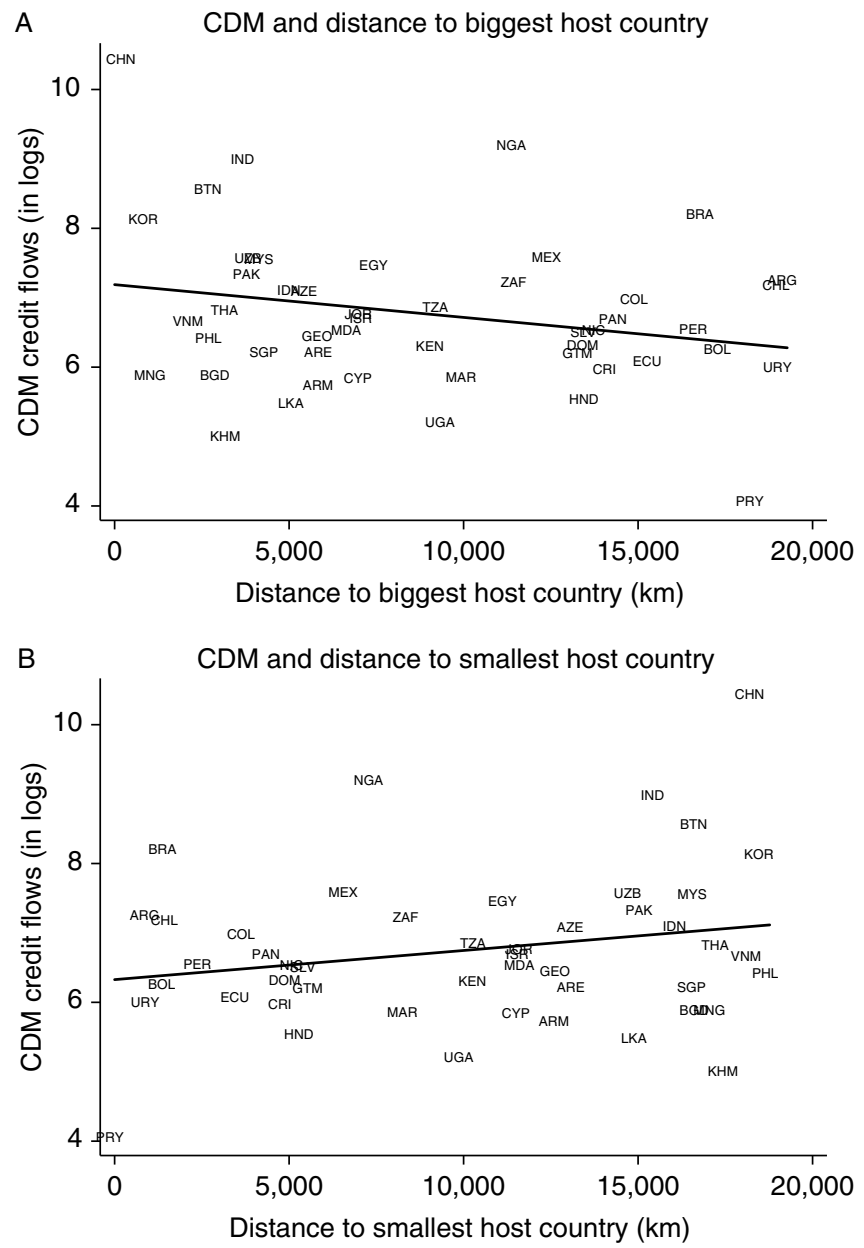

Figure 6.3 CDM and distance to biggest and smallest host countries

Note: Variables and data sources are described in the text. These figures show scatter plots of the distances to the biggest CDM host country (China) and to the smallest host country (Paraguay) against CDM credit flows (CERs). 
the upper chart, and the distance to the country with the smallest CDM credit flows in the lower chart. Data on the great circle distances are from Gleditsch et al. (2001). This figure clearly shows that countries closer to the biggest CDM host country, which is China, tend to have more CDM credit flows, whereas countries closer to the smallest CDM host country, which is Paraguay, tend to have fewer CDM credit flows. ${ }^{109}$ Countries with more (fewer) CDM credit flows appear to be geographically clustered with other larger (smaller) CDM host countries.

By using two different spatial weighting matrices, an inverse-distance spatial weighting matrix and a binary spatial weighting matrix, two standard test statistics of spatial autocorrelation have been calculated (Table 6.1). The inverse-distance spatial weighting matrix gives the inverse of the distance to each sample point within a $4000 \mathrm{~km}$ neighbourhood, and zero otherwise, while the binary spatial weighting matrix gives a weight of 1 to all sample points within a $4000 \mathrm{~km}$ neighbourhood, and zero otherwise. ${ }^{110}$ Both matrices are row-standardized of one. Following Kelejian and Prucha (1999), the spatial weighting matrices have been "idealized" so that each unit has the same number of neighbours with "one neighbour ahead and one neighbour behind" in a wraparound world.

Table 6.1 contrasts Moran's I and Gearcy's C statistics for CDM credit flows. Both Moran's I and Gearcy's C statistics examine the null hypothesis of no spatial dependence. No matter which matrix is chosen, the two Moran's I statistics are greater than the expected value $(-0.021)$ and the two Gearcy's C statistics are smaller than the expected value (1.000), suggesting positive spatial dependence of CDM credit flows

Table 6.1 Moran's I and Geary's C for CDM

\begin{tabular}{lccccc}
\hline & Moran's I & $\mathrm{E}(\mathrm{I})$ & $\mathrm{SD}(\mathrm{I})$ & $\boldsymbol{z}$-statistic & $\boldsymbol{p}$-value \\
\hline Inverse-distance Weights & 0.086 & -0.021 & 0.084 & 1.250 & {$[0.102]$} \\
Binary Weights & 0.094 & -0.021 & 0.067 & 1.714 & {$[0.043]^{* *}$} \\
& Gearcy's C & $\mathbf{E}(\mathrm{C})$ & $\mathrm{SD}(\mathrm{C})$ & $\boldsymbol{z}$-statistic & $\boldsymbol{p}$-value \\
Inverse-distance Weights & 0.902 & 1.000 & 0.092 & -1.064 & {$[0.144]$} \\
Binary Weights & 0.870 & 1.000 & 0.074 & -1.748 & {$[0.040]^{* *}$} \\
\hline
\end{tabular}

Notes: This table reports Moran's I and Gearcy's C tests for spatial autocorrelation for the averaged CDM credit flows in logs for 48 CDM host countries listed in the Appendix Table A6.1. The test statistics are calculated using an inverse-distance weighting matrix and a binary weighting matrix, respectively, as described in the text.

* significant at $10 \%$; ${ }^{* *}$ significant at $5 \%$; *** significant at $1 \%$. 
across countries. ${ }^{111}$ Moreover, both Moran's I and Gearcy's C statistics reject the null at about 10\% significance level with an inverse-distance spatial weighting matrix, and at 5\% significance level with a binary spatial weighting matrix. This shows that the positive spatial dependence of the CDM credit flows is significant across countries.

Tables 6.2 and 6.3 investigate whether countries with particular geographic endowments are more likely to attract CDM projects, for which eight geographic endowment variables, as explained earlier, are selected from various sources. ${ }^{112}$

Column 1 of Table 6.2 reports the OLS estimates for the non-spatial model (6.1). Firstly, an OLS heteroscedasticity test following White (1980) and Koenker (1981) is conducted to examine whether there is heteroscedasticity in the estimation regression which is related to any of the geographic variables we examine. ${ }^{113}$ The White/Koenker test rejects the null at $10 \%$ significance level, indicating that heteroscedasticity exists in the estimations and should be taken into account for this context.

To test for which type(s) of spatial dependence, spatial lag dependence or spatial error dependence or both, exist(s) in this context, we carry out two simple Lagrange Multiplier tests (LM) separately. The hypothesis of no spatially lagged dependent variable is rejected at about $10 \%$ significance level while the hypothesis of no spatially autocorrelated error term can not be rejected. Furthermore, the p-values for the robust LM tests following Anselin et al. (1996) and the log-likelihood statistics are reported to test for whether a spatial lag model is more appropriate than a spatial error model for this context. The evidence that the robust LM test doesn't reject the null hypothesis of no spatially autocorrelated error term, but does reject the null of no spatially lagged dependent variable (at about 10\% significance level), together with the evidence that the log-likelihood statistic for the spatial lag model (-41.03) is bigger than that for the spatial error model (-41.61), suggest that a spatial lag model is preferred to a spatial error model.

Columns 2 to 4 report the ML estimates for the spatial lag model (6.2) and spatial error model (6.3), and the GS2SLS estimates following Kelejian and Prucha (2010) for the SARAR(1,1) model (6.4). An inversedistance spatial weighting matrix has been used to calculate the ML estimates and GS2SLS estimates. ${ }^{114}$

The spatial autocorrelation parameter, " $\rho$ " appears to be insignificant in both the spatial error model and the $\operatorname{SARAR}(1,1)$ model. For the spatial autoregressive parameter, " $\lambda$ ", $\rho$ has been found weakly significant in the spatial lag model and significant in the SARAR $(1,1)$ model, with larger coefficient in the SARAR $(1,1)$ model. The GS2SLS estimate of " $\lambda$ " in the 
Table 6.2 Geography and CDM (by inverse-distance weights)

\begin{tabular}{|c|c|c|c|c|}
\hline & $\begin{array}{c}\text { Non-spatial } \\
\text { model }\end{array}$ & $\begin{array}{l}\text { Spatial Lag } \\
\text { model }\end{array}$ & $\begin{array}{l}\text { Spatial Error } \\
\text { model }\end{array}$ & $\operatorname{SARAR}(1,1)$ \\
\hline$\lambda$ & & $\begin{array}{c}0.185 \\
{[0.135]}\end{array}$ & & $\begin{array}{l}0.339 \\
{[0.033]^{* *}}\end{array}$ \\
\hline$\rho$ & & & $\begin{array}{c}0.315 \\
{[0.226]}\end{array}$ & $\begin{array}{c}-0.300 \\
{[0.239]}\end{array}$ \\
\hline LATITUDE & $\begin{array}{c}0.016 \\
{[0.090]^{*}}\end{array}$ & $\begin{array}{c}0.017 \\
{[0.088]^{*}}\end{array}$ & $\begin{array}{c}0.016 \\
{[0.111]}\end{array}$ & $\begin{array}{c}0.018 \\
{[0.140]}\end{array}$ \\
\hline ELEVATION & $\begin{array}{c}0.276 \\
{[0.048]^{* *}}\end{array}$ & $\begin{array}{c}0.270 \\
{[0.008]^{* * *}}\end{array}$ & $\begin{array}{c}0.255 \\
{[0.012]^{* *}}\end{array}$ & $\begin{array}{c}0.274 \\
{[0.031]^{* *}}\end{array}$ \\
\hline$A R E A$ & $\begin{array}{c}0.155 \\
{[0.150]}\end{array}$ & $\begin{array}{c}0.135 \\
{[0.173]}\end{array}$ & $\begin{array}{c}0.125 \\
{[0.219]}\end{array}$ & $\begin{array}{c}0.118 \\
{[0.331]}\end{array}$ \\
\hline EXPSERV & $\begin{array}{l}0.965 \\
{[0.004]^{* * *}}\end{array}$ & $\begin{array}{l}0.888 \\
{[0.002]^{* * *}}\end{array}$ & $\begin{array}{l}0.851 \\
{[0.004]^{* * *}}\end{array}$ & $\begin{array}{l}0.860 \\
{[0.020]^{* *}}\end{array}$ \\
\hline EXPPRIM & $\begin{array}{c}-0.287 \\
{[0.368]}\end{array}$ & $\begin{array}{c}-0.320 \\
{[0.211]}\end{array}$ & $\begin{array}{c}-0.337 \\
{[0.184]}\end{array}$ & $\begin{array}{c}-0.307 \\
{[0.333]}\end{array}$ \\
\hline RESPOINT & $\begin{array}{l}-1.587 \\
{[0.013]^{* *}}\end{array}$ & $\begin{array}{l}-1.642 \\
{[0.000]^{* * *}}\end{array}$ & $\begin{array}{l}-1.565 \\
{[0.000]^{* * *}}\end{array}$ & $\begin{array}{l}-1.678 \\
{[0.002]^{* * *}}\end{array}$ \\
\hline RESDIFF & $\begin{array}{l}-1.059 \\
{[0.013]^{* *}}\end{array}$ & $\begin{array}{c}-1.098 \\
{[0.002]^{* * *}}\end{array}$ & $\begin{array}{l}-0.998 \\
{[0.005]^{* * *}}\end{array}$ & $\begin{array}{l}-1.147 \\
{[0.010]^{* * *}}\end{array}$ \\
\hline RESCOFF & $\begin{array}{l}-1.368 \\
{[0.022]^{* *}}\end{array}$ & $\begin{array}{l}-1.484 \\
{[0.001]^{* * *}}\end{array}$ & $\begin{array}{l}-1.435 \\
{[0.001]^{* * *}}\end{array}$ & $\begin{array}{l}-1.525 \\
{[0.011]^{* *}}\end{array}$ \\
\hline GDPO3 & $\begin{array}{c}0.258 \\
{[0.259]}\end{array}$ & $\begin{array}{c}0.236 \\
{[0.090]^{*}}\end{array}$ & $\begin{array}{c}0.279 \\
{[0.056]^{*}}\end{array}$ & $\begin{array}{c}0.185 \\
{[0.264]}\end{array}$ \\
\hline РОРО3 & $\begin{array}{l}0.360 \\
{[0.004]^{* * *}}\end{array}$ & $\begin{array}{l}0.366 \\
{[0.001]^{* * *}}\end{array}$ & $\begin{array}{l}0.367 \\
{[0.001]^{* * *}}\end{array}$ & $\begin{array}{c}0.360 \\
{[0.007]^{* * *}}\end{array}$ \\
\hline ETHNIC & $\begin{array}{c}1.336 \\
{[0.050]^{*}}\end{array}$ & $\begin{array}{l}1.467 \\
{[0.015]^{* *}}\end{array}$ & $\begin{array}{l}1.367 \\
{[0.031]^{* *}}\end{array}$ & $\begin{array}{c}1.606 \\
{[0.027]^{* *}}\end{array}$ \\
\hline REGLIGION & $\begin{array}{l}2.077 \\
{[0.013]^{* *}}\end{array}$ & $\begin{array}{l}2.067 \\
{[0.000]^{* * *}}\end{array}$ & $\begin{array}{l}2.061 \\
{[0.000]^{* * *}}\end{array}$ & $\begin{array}{l}2.001 \\
{[0.004]^{* * *}}\end{array}$ \\
\hline COMLEG & $\begin{array}{c}0.557 \\
{[0.261]}\end{array}$ & $\begin{array}{c}0.541 \\
{[0.117]}\end{array}$ & $\begin{array}{c}0.520 \\
{[0.135]}\end{array}$ & $\begin{array}{c}0.552 \\
{[0.190]}\end{array}$ \\
\hline CIVLEG & $\begin{array}{l}1.278 \\
{[0.046]^{* *}}\end{array}$ & $\begin{array}{l}1.354 \\
{[0.004]^{* * *}}\end{array}$ & $\begin{array}{l}1.393 \\
{[0.003]^{* * *}}\end{array}$ & $\begin{array}{l}1.331 \\
{[0.022]^{* *}}\end{array}$ \\
\hline Constant & $\begin{array}{l}-4.312 \\
{[0.074]^{*}}\end{array}$ & $\begin{array}{l}-5.175 \\
{[0.003]^{* * *}}\end{array}$ & $\begin{array}{l}-4.064 \\
{[0.018]^{* *}}\end{array}$ & $\begin{array}{l}-5.571 \\
{[0.006]^{* * *}}\end{array}$ \\
\hline Observations & 48 & 48 & 48 & 48 \\
\hline$R$-squared & 0.73 & 0.74 & 0.72 & \\
\hline $\begin{array}{l}\text { Log Likelihood } \\
\text { White/Koenker test }\end{array}$ & [0.105] & -41.03 & -41.61 & \\
\hline Spatial lag: & & & & \\
\hline $\begin{array}{l}\text { LM } \\
\text { Robust LM }\end{array}$ & $\begin{array}{l}{[0.107]} \\
{[0.107]}\end{array}$ & & & \\
\hline $\begin{array}{l}\text { Spatial error: } \\
\text { LM } \\
\text { Robust LM }\end{array}$ & $\begin{array}{l}{[0.572]} \\
{[0.570]}\end{array}$ & & & \\
\hline
\end{tabular}

Notes: Dependent variable is the averaged CDM credit flows (2012 kCERs) in logs. Robust p-values are reported in brackets. Variables and data sources are described in text. $\lambda$ is the spatial autoregressive parameter in dependent variable in the spatial lag model and SARAR $(1,1)$ model, whilst $\rho$ is the spatial autoregressive parameter in the disturbance in spatial error model and SARAR $(1,1)$ model. The White/Koenker test is to examine the null of no heteroscedasticity. The spatial weighting matrix used here is a row-standardized inverse-distance weighting matrix described in the text. Robust p-values are reported in brackets.

* significant at $10 \%$; $*$ significant at $5 \%$; *** significant at $1 \%$. 
SARAR $(1,1)$ model shows that the CDM credit flows in a country increase by 0.34 units if those in its neighbouring countries increase by one unit.

The explanatory variables described in Section 6.2, except for EXPMANU, have been found to be closely related to CDM credit flows with the expected signs. In particular, the GS2SLS estimates show that the the geographic variables LATITUDE and ELEV are positively associated with CDM development. For the resource and commodity exporter dummies, EXPSERV is positively related, while RESPOINT, RESDIFF and $R E S C O F F$ are negatively related, to CDM development. All of the control variables including GDP03, POP03, ETHNIC, RELIGION and legal origin dummies (CIVLEG, COMLEG) are in general found significantly associated with CDM development and should be included in the model. ${ }^{115}$

With a row-standardized binary weighting matrix, Table 6.3 in general confirms the findings of Table 6.2 in terms of positive impacts of LATITUDE, ELEV and EXPSERV, and negative impacts of RESPOINT, RESDIFF and RESCOFF on CDM credit flows. Table 6.3 seems to provide stronger evidence than Table 6.2, especially for the spatial autoregressive coefficients, " $\lambda$ " and " $\rho$ ". According to the $\operatorname{SARAR}(1,1)$ model, the degree of neighbourhood effects for the CDM credit flows increases to 0.48 .

The finding on the positive association between absolute latitude and CDM credit flows is consistent with the literature. On the one hand, research by Diamond (1997), Gallup et al. (1999) and Sachs (2003a) suggests that countries in a tropical location in terms of a smaller absolute latitude are often associated with poor crop yields and production due to adverse ecological conditions such as fragile tropical soils, unstable water supply and prevalence of crop pests. On the other hand, tropical location can be characterized as an inhospitable disease environment, believed to be a primary cause for "extractive" institutions, in conjunction with weaker institutions according to the settler mortality hypothesis of Acemoglu et al. (2001). Countries further from the Equator are more likely to have better climate conditions and stronger institutions, which are conducive to CDM project development.

The finding on the positive association between elevation and CDM credit flows is in line with recent research. It is widely known that the Earth's average surface temperature rose by approximately $0.6^{\circ} \mathrm{C}$ in the twentieth century and will rise a few degrees $\mathrm{C}$ in this century. Global warming is likely to raise the sea level and change the land area and elevation above sea level for many countries. Countries with higher elevations are therefore supposed to have more potential to attract CDM projects. 
Table 6.3 Geography and CDM (by binary weights)

\begin{tabular}{|c|c|c|c|c|}
\hline & $\begin{array}{l}\text { Non-spatial } \\
\text { model }\end{array}$ & $\begin{array}{l}\text { Spatial Lag } \\
\text { model }\end{array}$ & $\begin{array}{l}\text { Spatial Error } \\
\text { model }\end{array}$ & $\operatorname{SARAR}(1,1)$ \\
\hline$\lambda$ & & $\begin{array}{c}0.288 \\
{[0.068]^{*}}\end{array}$ & & $\begin{array}{l}0.476 \\
{[0.023]^{* *}}\end{array}$ \\
\hline$\rho$ & & & $\begin{array}{l}0.495 \\
{[0.041]^{* *}}\end{array}$ & $\begin{array}{c}-0.299 \\
{[0.205]}\end{array}$ \\
\hline LATITUDE & $\begin{array}{c}0.016 \\
{[0.090]^{*}}\end{array}$ & $\begin{array}{c}0.018 \\
{[0.065]^{*}}\end{array}$ & $\begin{array}{l}0.016 \\
{[0.094]^{*}}\end{array}$ & $\begin{array}{c}0.020 \\
{[0.108]}\end{array}$ \\
\hline ELEVATION & $\begin{array}{l}0.276 \\
{[0.048]^{* *}}\end{array}$ & $\begin{array}{l}0.255 \\
{[0.011]^{* *}}\end{array}$ & $\begin{array}{l}0.232 \\
{[0.018]^{* *}}\end{array}$ & $\begin{array}{l}0.256 \\
{[0.047]^{* *}}\end{array}$ \\
\hline AREA & $\begin{array}{c}0.155 \\
{[0.150]}\end{array}$ & $\begin{array}{c}0.115 \\
{[0.244]}\end{array}$ & $\begin{array}{c}0.118 \\
{[0.232]}\end{array}$ & $\begin{array}{c}0.087 \\
{[0.479]}\end{array}$ \\
\hline EXPSERV & $\begin{array}{l}0.965 \\
{[0.004]^{* * *}}\end{array}$ & $\begin{array}{l}0.831 \\
{[0.004]^{* * *}}\end{array}$ & $\begin{array}{l}0.779 \\
{[0.006]^{* * *}}\end{array}$ & $\begin{array}{l}0.796 \\
{[0.034]^{* *}}\end{array}$ \\
\hline EXPPRIM & $\begin{array}{c}-0.287 \\
{[0.368]}\end{array}$ & $\begin{array}{c}-0.334 \\
{[0.187]}\end{array}$ & $\begin{array}{c}-0.401 \\
{[0.118]}\end{array}$ & $\begin{array}{c}-0.319 \\
{[0.306]}\end{array}$ \\
\hline RESPOINT & $\begin{array}{l}-1.587 \\
{[0.013]^{* *}}\end{array}$ & $\begin{array}{l}-1.671 \\
{[0.000]^{* * *}}\end{array}$ & $\begin{array}{l}-1.574 \\
{[0.000]^{* * *}}\end{array}$ & $\begin{array}{l}-1.717 \\
{[0.002]^{* * *}}\end{array}$ \\
\hline RESDIFF & $\begin{array}{l}-1.059 \\
{[0.013]^{* *}}\end{array}$ & $\begin{array}{l}-1.127 \\
{[0.001]^{* * *}}\end{array}$ & $\begin{array}{l}-1.023 \\
{[0.003]^{* * *}}\end{array}$ & $\begin{array}{l}-1.182 \\
{[0.008]^{* * *}}\end{array}$ \\
\hline RESCOFF & $\begin{array}{l}-1.368 \\
{[0.022]^{* *}}\end{array}$ & $\begin{array}{l}-1.515 \\
{[0.001]^{* * *}}\end{array}$ & $\begin{array}{l}-1.529 \\
{[0.001]^{* * *}}\end{array}$ & $\begin{array}{l}-1.546 \\
{[0.009]^{* * *}}\end{array}$ \\
\hline GDP03 & $\begin{array}{c}0.258 \\
{[0.259]}\end{array}$ & $\begin{array}{c}0.220 \\
{[0.111]}\end{array}$ & $\begin{array}{l}0.267 \\
{[0.063]^{*}}\end{array}$ & $\begin{array}{c}0.162 \\
{[0.325]}\end{array}$ \\
\hline РОРО3 & $\begin{array}{l}0.360 \\
{[0.004]^{* * *}}\end{array}$ & $\begin{array}{l}0.382 \\
{[0.000]^{* * *}}\end{array}$ & $\begin{array}{l}0.358 \\
{[0.001]^{* * *}}\end{array}$ & $\begin{array}{l}0.392 \\
{[0.004]^{* * *}}\end{array}$ \\
\hline ETHNIC & $\begin{array}{c}1.336 \\
{[0.050]^{*}}\end{array}$ & $\begin{array}{l}1.581 \\
{[0.009]^{* * *}}\end{array}$ & $\begin{array}{l}1.395 \\
{[0.027]^{* *}}\end{array}$ & $\begin{array}{l}1.765 \\
{[0.018]^{* *}}\end{array}$ \\
\hline REGLIGION & $\begin{array}{l}2.077 \\
{[0.013]^{* *}}\end{array}$ & $\begin{array}{l}1.940 \\
{[0.000]^{* * *}}\end{array}$ & $\begin{array}{l}2.011 \\
{[0.000]^{* * *}}\end{array}$ & $\begin{array}{l}1.834 \\
{[0.006]^{* * *}}\end{array}$ \\
\hline COMLEG & $\begin{array}{c}0.557 \\
{[0.261]}\end{array}$ & $\begin{array}{c}0.559 \\
{[0.101]}\end{array}$ & $\begin{array}{c}0.482 \\
{[0.150]}\end{array}$ & $\begin{array}{c}0.602 \\
{[0.155]}\end{array}$ \\
\hline CIVLEG & $\begin{array}{l}1.278 \\
{[0.046]^{* *}}\end{array}$ & $\begin{array}{l}1.407 \\
{[0.002]^{* * *}}\end{array}$ & $\begin{array}{l}1.408 \\
{[0.002]^{* * *}}\end{array}$ & $\begin{array}{l}1.457 \\
{[0.014]^{* *}}\end{array}$ \\
\hline Constant & $\begin{array}{l}-4.312 \\
{[0.074]^{*}}\end{array}$ & $\begin{array}{l}-5.591 \\
{[0.001]^{* * *}}\end{array}$ & $\begin{array}{l}-3.544 \\
{[0.042]^{* *}}\end{array}$ & $\begin{array}{l}-6.221 \\
{[0.003]^{* * *}}\end{array}$ \\
\hline Observations & 48 & 48 & 48 & 48 \\
\hline$R$-squared & 0.73 & 0.75 & 0.71 & \\
\hline $\begin{array}{l}\text { Log Likelihood } \\
\text { White/Koenker test }\end{array}$ & {$[0.105]$} & -40.56 & -40.99 & \\
\hline $\begin{array}{l}\text { Spatial lag: } \\
\text { LM } \\
\text { Robust LM }\end{array}$ & $\begin{array}{l}{[0.055]^{*}} \\
{[0.070]^{*}}\end{array}$ & & & \\
\hline $\begin{array}{l}\text { Spatial error: } \\
\text { LM } \\
\text { Robust LM }\end{array}$ & $\begin{array}{l}{[0.385]} \\
{[0.563]}\end{array}$ & & & \\
\hline
\end{tabular}

Notes: The spatial weighting matrix used for the spatial lag model, spatial error model and SARAR $(1,1)$ model in this table is arow-standardized binary weighting matrix described in the text. See Table 6.2 for more notes. 
Some growth literature indicates that natural resource abundance is connected with social and economic instability and weak institutional quality, which hamper CDM project development. Isham et al. (2005) find that, in comparison to manufacturing exporters, the exporting countries of "point source" natural resources (e.g. oil, diamonds, plantation crops) and coffee/cocoa natural resources are more likely to have severe social and economic divisions, and less likely to develop socially cohesive mechanisms and effective institutional capacities for managing shocks.

In sum, this research produces the following significant findings. First, it provides evidence for the presence of positive spatial dependence amongst observations for this context, especially the spatial lag dependence associated with neighbourhood effects and social interactions. CDM credit flows in a country are significantly affected by those of its neighbouring countries, more specifically, the CDM credit flows in a country increase by about 0.34 to 0.48 units if those in its neighbouring countries increase by one unit. Second, by allowing for spatial dependence and accounting for the size of the economy (initial population and initial GDP per capita), this research finds that the absolute latitude and elevation have positive impacts on CDM credit flows, suggesting that countries further from the Equator and having a higher elevation tend to initiate more CDM projects and issue more CDM credit flows. Countries with more exports of services seem to have more advantages in attracting CDM projects, whilst in contrast countries with more exports of natural resources have smaller CDM credit flows, indicating that natural resource abundance may not necessarily be conducive to CDM development.

\subsection{Concluding remarks}

Under the Kyoto Protocol, the Clean Development Mechanism (CDM) is designed to provide the non-Annex I countries (developing countries and transition economies) with access to the flows of technology and capital which could contribute to their sustainable development objectives, whilst allowing Annex I countries to earn credits to meet their Kyoto commitments by investing in GHG emission reduction projects in non-Annex I countries.

This chapter investigates whether the cross-sectional differences in geographic endowments can explain the cross-sectional differences in CDM credit flows. It conducts a cross-country study allowing for both spatial error dependence and spatial lag dependence for 48 CDM host countries over December 2003-September 2008. 
This research leads to two significant findings. First, it provides evidence for a positive relationship between CDM credit flows in a country and those in its neighbours, more specifically, the CDM credit flows in a country increase by about 0.34 to 0.48 units if those in its neighbours increase by one unit. Countries with larger (smaller) CDM credit flows have been found to be geographically clustered with other larger (smaller) CDM host countries. Second, by allowing for spatial dependence and accounting for the size of the economy (initial population and initial GDP per capita), this research finds that absolute latitude and elevation have positive impacts on CDM credit flows, suggesting that countries further from the equator and having higher elevations are in better positions to attract CDM projects. Countries with more exports of service are more associated with larger CDM credit flows, whilst in contrast countries with more exports of natural resources have fewer CDM credit flows, indicating that natural resource abundance doesn't necessarily play a large role in promoting CDM development. These findings are robust to the choices of different spatial weighting matrices - an inverse-distance spatial weighting matrix and a binary spatial weighting matrix. The research also controls for an ethnic fractionalization index, a religious fractionalization index and legal origin dummies.

This finding sheds light on the geographic determinants of uneven $\mathrm{CDM}$ project development across countries, and has rich implications for developing countries in terms of international cooperation and national capacity building to access effectively CDM for their national sustainable development objective. This research may contribute to our understanding of the cross-country differences in CDM development and contain some merits for the UNFCCC in terms of improving the geographic distribution of CDM project activities and capacity building. This research also suggests that geographic considerations should be introduced into the econometric and theoretical cross-country studies of climate change and mitigation. 


\section{Appendix table}

Table A6.1 The list of countries in the full sample

\begin{tabular}{llll}
\hline Code & Country name & Code & Country name \\
\hline ARE & United Arab Emirates & KHM & Cambodia \\
ARG & Argentina & KOR & Korea, Rep. \\
ARM & Armenia & LKA & Sri Lanka \\
AZE & Azerbaijan & MAR & Morocco \\
BGD & Bangladesh & MDA & Moldova, Rep. \\
BOL & Bolivia & MEX & Mexico \\
BRA & Brazil & MNG & Mongolia \\
BTN & Bhutan & MYS & Malaysia \\
CHL & Chile & NGA & Nigeria \\
CHN & China & NIC & Nicaragua \\
COL & Colombia & PAK & Pakistan \\
CRI & Costa Rica & PAN & Panama \\
CYP & Cyprus & PER & Peru \\
DOM & Dominican Rep. & PHL & Philippines \\
ECU & Ecuador & PRY & Paraguay \\
EGY & Egypt, Arab Rep. & SGP & Singapore \\
GEO & Georgia & SLV & El Salvador \\
GTM & Guatemala & THA & Thailand \\
HND & Honduras & TZA & Tanzania \\
IDN & Indonesia & UGA & Uganda \\
IND & India & URY & Uruguay \\
ISR & Israel & UZB & Uzbekistan \\
JOR & Jordan & VNM & Vietnam \\
KEN & Kenya & ZAF & South Africa \\
& & & \\
\hline & & & \\
\hline
\end{tabular}

Note: This table lists the country codes and country names for $48 \mathrm{CDM}$ host countries considered in this analysis. Data are from the UNEP Risoe Centre CDM/JI Pipeline Analysis and Database (2008). 